\title{
A Study on the Computed Tomography Evaluation of Neck Masses
}

\author{
Ashish Chaturvedi ${ }^{1}$, DS Grewal ${ }^{2}$ \\ ${ }^{1}$ Assistant Professor, Department of Radiodiagnosis, Varun Arjun Rohilkhand Medical College \& Rohilkhand Hospital, \\ Shahjahanpur, UP, ${ }^{2}$ Professor \& Head, Department of Radiodiagnosis, Varun Arjun Rohilkhand Medical College \& Rohilkhand \\ Hospital, Shahjahanpur, UP, India
}

Corresponding author: Dr (Col.) DS Grewal, Professor \& Head, Department of Radiodiagnosis, Varun Arjun Rohilkhand Medical College \& Rohilkhand Hospital, Shahjahanpur, UP, India

DOI: http://dx.doi.org/10.21276/ijcmsr.2020.5.1.44

BY-NC-ND

How to cite this article: Ashish Chaturvedi, DS Grewal. A study on the computed tomography evaluation of neck masses. International Journal of Contemporary Medicine Surgery and Radiology. 2020;5(1):A203-A205.

\section{A B S T R A C T}

introduction: CT has been proved to be sensitive and reliable in the prediction of many disease processes. Study aimed to assess the utility of MDCT in detecting neck masses to provide information which can accurately determines the choice of management.

Material and methods: A total of 59 patients with neck mass lesions from various clinical departments of the institute were prospectively evaluated using multi slice spiral CT scan of the neck. Non-contrast with contrast-enhanced computed tomography was performed among all patients.

Results: More than one third of cases were between $40-50$ years of age (47.5\%). The mean age was $48.36 \pm 13.36$ years with range $16-85$ years. More than half of cases were males (78\%). Lymph Nodal mass was the most common neck mass (39\%) followed by Nerve sheath tumors (13.2\%) and Miscellaneous (10.2\%). The percentage of other neck masses was less than $10 \%$. The sensitivity and specificity of MDCT for diagnosing benign lesions was $72.2 \%$ and $69.6 \%$ respectively with positive predictive value of $78.8 \%$ and for malignant lesions sensitivity was $30.4 \%$, specificity was $27.8 \%$ and positive predictive value of $21.2 \%$.

Conclusion: The accuracy of MDCT to predict benign or malignant lesion of the neck massed was observed to be high.

Keywords: Computed Tomography, Neck Masses, Predictive Values

\section{INTRODUCTION}

A mass lesion in the neck can be a diagnostic challenge in a patient of any age. Neck masses include a spectrum of lesions of diverse origin and etiology. The clinical investigation alone is limited to accurately assess the extent as well as size of head and neck tumors. Specifically, submucosal extension of disease and extent of nodal metastasis. ${ }^{1}$ Computed tomography (CT) has found an increasing application in the evaluation of neck masses-both congenital and acquired. It is currently one of the most powerful and versatile imaging techniques in the evaluation of neck masses. $^{2}$

Neck masses may be classified into 2 types: i) Nodal masses and ii) Non-nodal masses. Both types may seem as benign or malignant lesions. With a detailed physical investigation and endoscopy, imaging has become essential in the characterization as well as staging of neck masses. CT provides indispensible information about the deep extension of clinically detected masses. It may delineate additional clinically unsuspected lesions. The application of Multi-detector CT has resulted in improved resolution as well as significant decrease in scan acquisition time. The other benefits are improved temporal resolution into arterial
\& venous phases, volume acquisition of data enabling convenient retrospective reconstructions, isotropic viewing and unlimited reformations leading to increased lesion conspicuity. ${ }^{3}$

$\mathrm{CT}$ is a new method of developing images from $\mathrm{X}$-rays. It was introduced into clinical use by the British physicist Godfrey Hounsfield in 1972. It has a wonderful impact in the field of diagnostic radiology. The introduction of multi-detector CT (MDCT) into clinical practice in 1998 instituted a fundamental evolutionary step in the development and ongoing refinement of CT imaging procedures. This promising 3-dimensional imaging tool allows substantial anatomical volumes to be routinely covered with isotropic sub-millimeter spatial resolution. ${ }^{4}$ The ability of highresolution MDCT scans to accurately localize the lesions and biopsy needles, along with the delineation of adjacent structures, diagnostic fine-needle aspiration for both benign and malignant disease processes has become a quite safe and highly accurate procedure. ${ }^{5}$

The present study was designed to assess the ability of MDCT in detection of neck masses and provide information that could accurately determine the choice of management. 


\section{MATERIAL AND METHODS}

A total of 59 patients with neck mass lesions from various clinical departments of the institute were prospectively evaluated using multi slice spiral CT scan of the neck. Noncontrast with contrast-enhanced computed tomography was performed among all patients. The effectiveness of CT examination concerning the prediction of nature of mass (benign/malignant), its localization, local extent and correlation with final clinical / cytological/ surgical diagnosis was performed. The accuracy calculated as the percentage of cases where CT findings correctly matched with clinical / cytological/ surgical findings.

All these patient were submitted to detail clinical examination, routine investigation \& subsequently submitted for CT scan of neck. The area of scanning was defined to include the region from base of skull to aorto pulmonary window. Axial sections was taken with patient in supine position $\&$ plane of data acquisition was parallel to hard palate. All the scans were then be evaluated in three planes: - Axial, sagittal, coronal planes.

\section{STATISTICAL METHODS}

The results are presented in mean $\pm \mathrm{SD}$ and percentages. The Chi-square test was used to compare the categorical variables. The sensitivity, specificity, positive predictive value (PPV), negative predictive value (NPV), accuracy and likelihood ratios of MDCT was calculated. The $\mathrm{p}$-value $<0.05$ was considered significant. All the analysis was carried out on SPSS 16.0 version (Chicago, Inc., USA).

\section{RESULTS}

More than one third of cases were between 40-50 years of age $(47.5 \%)$. The mean age was $48.36 \pm 13.36$ years with range 16-85 years. Majority of cases were males (78\%) (Table-1).

Benign lesion was in $55.9 \%$ and malignant was $44.1 \%$. Parathyroid adenoma was the most common benign lesions followed by goiter (12.1\%). The percentage of other lesions was less than 10\%. Primary malignancy was the most common malignant lesions followed by Metastatic lymph nodes (19.2\%) and Primary lymphoma (11.5). The percentage of other lesions was less than 10\% (Table-2).

Lymph Nodal mass was the most common neck mass (39\%) followed by Nerve sheath tumors (13.2\%) and Miscellaneous (10.2\%). The percentage of other neck masses was less than 10\% (Table-3).

The sensitivity and specificity of MDCT for diagnosing

\begin{tabular}{|l|c|c|}
\hline Age and gender & $\begin{array}{c}\text { No. } \\
(\mathbf{n}=\mathbf{5 9})\end{array}$ & \% \\
\hline Age in years & & 16.9 \\
\hline$<40$ & 10 & 47.5 \\
\hline $40-50$ & 28 & 35.6 \\
\hline$>50$ & 21 & \\
\hline Mean \pm SD (Range) & $48.36 \pm 13.36(16-85)$ & \\
\hline Gender & 46 & 22.0 \\
\hline Male & 13 & 2.0 \\
\hline Female & & \\
\hline \multicolumn{2}{|c|}{ Table-1: Age and gender distribution of cases } \\
\hline
\end{tabular}

\begin{tabular}{|l|c|c|}
\hline Nature & $\begin{array}{c}\text { No. } \\
\text { (n=59) }\end{array}$ & \% \\
\hline Benign & 33 & 55.9 \\
\hline Parathyroid adenoma & 10 & 30.3 \\
\hline Goitre & 4 & 12.1 \\
\hline Colloid cyst & 2 & 6.1 \\
\hline Angiofibroma & 3 & 9.1 \\
\hline Schwannoma & 3 & 9.1 \\
\hline Paraganglioma & 3 & 9.1 \\
\hline Multinodular goiter & 2 & 6.1 \\
\hline Warthin's tumour & 2 & 6.1 \\
\hline Pleomorphic adenoma & 2 & 6.1 \\
\hline Retention cyst (parotid) & 2 & 6.1 \\
\hline Malignant & 26 & 44.1 \\
\hline Metastatic lymph nodes & 5 & 19.2 \\
\hline Primary lymphoma & 3 & 11.5 \\
\hline Primary malignancy & 10 & 38.5 \\
\hline Thyroid malignancy & 3 & 11.5 \\
\hline Ca soft palate & 1 & 3.8 \\
\hline Ca buccal mucosa & 2 & 7.7 \\
\hline Ca oropharynx & 2 & 7.7 \\
\hline Table-2: Distribution of cases according to nature of neck mass \\
\hline
\end{tabular}

\begin{tabular}{|l|c|c|}
\hline Neck masses & $\begin{array}{c}\text { No. } \\
(\mathbf{n = 5 9 )}\end{array}$ & \% \\
\hline Lymph Nodal mass & 23 & 39.0 \\
\hline Thyroid lesions & 5 & 8.5 \\
\hline Vascular Malformations & 5 & 8.5 \\
\hline Developmental lesions & 6 & 10.2 \\
\hline Inflammatory lesions & 2 & 3.4 \\
\hline Salivary gland lesions & 4 & 6.8 \\
\hline Nerve sheath tumors & 8 & 13.6 \\
\hline Miscellaneous & 6 & 10.2 \\
\hline \multicolumn{2}{|c|}{ Table-3: Spectrum of different neck masses } \\
\hline
\end{tabular}

\begin{tabular}{|l|c|c|}
\hline Diagnostic parameters & Benign & Malignant \\
\hline Sensitivity & 72.2 & 30.4 \\
\hline Specificity & 69.6 & 27.8 \\
\hline Positive predictive value (PPV) & 78.8 & 21.2 \\
\hline Negative predictive value (NPV) & 61.5 & 38.5 \\
\hline Accuracy & 71.2 & 28.8 \\
\hline Likelihood ratio (LR) + & 2.4 & 0.4 \\
\hline Likelihood ratio (LR) - & 0.4 & 2.5 \\
\hline \multicolumn{2}{|c|}{ Table-4: Distribution of diagnostic accuracy of MDCT } \\
\hline
\end{tabular}

benign lesions was $72.2 \%$ and $69.6 \%$ respectively with a positive predictive value of $78.8 \%$ and for malignant lesions sensitivity $30.4 \%$, specificity was $27.8 \%$, positive predictive value of $21.2 \%$ (Table-4).

\section{DISCUSSION}

The detailed physical examination as well as modern endoscopy, the imaging had become essential in the characterization and staging of neck pathology. ${ }^{6}$ It is noninvasive, non-operator dependent and allows the precise measurement of tissue attenuation coefficient. However, spiral CT increases the examination quality, reducing the 
sedation time and requiring lower radiation doses. ${ }^{7}$ Multi slice spiral CT using multiple detector rows is the latest development in CT technology. Use of multiple detector rows allows faster scanning and thinner collimation. ${ }^{8}$

Multidetector CT permits rapid scanning of large volumes of tissue during quiet respiration. ${ }^{9}$ Spiral images have less susceptible to patient motion compared to conventional CT, however, image noise is somewhat increased. Volumetric helical data allow the optimal multi-planar as well as 3-dimensional reconstructions. Moreover, spectacular CT angiograms may be produced with the data. ${ }^{6}$

In the study of 59 cases of neck masses, more than one third of cases were between $40-50$ years of age (47.5\%). The mean age was $48.36 \pm 13.36$ years with range $16-85$ years. Majority of cases were males (78\%). In the study by Ravi et al, the age range was from 0 years to 80 years. The most of patients were in $41-50$ years (22\%) age group followed by 31-40 years $(18 \%)$. Of the total cases, 66 cases were males with male to female ratio of $1.9: 1 .^{3}$

In this study, benign lesion was in $55.9 \%$ and malignant was $44.1 \%$. In the study by Thakkar et al, out of the 100 cases studied, 34 (34\%) were of malignant etiology, 24 (24\%) were of benign etiology, 33 (33\%) were of inflammatory etiology, $6(6 \%)$ were congenital and 3(3\%) were of vascular etiology. ${ }^{10}$ In the present study, the primary malignancy was the most common malignant lesions followed by Metastatic lymph nodes (19.2\%) and Primary lymphoma (11.5\%). The percentage of other lesions was less than $10 \%$. Thakkar et al showed that the most common primary malignant lesion in the neck was carcinoma of pyriform fossa (hypopharynx) 6 out of 34 cases (17.64\%) and thyroid carcinoma 5 out of 34 cases $(14.70 \%) .{ }^{10}$ In the study by Lasrado et al, the most common site of primary malignant lesion in the neck was larynx(19.6\%), followed by the thyroid(14.4\%), the tongue and hypopharynx with $10.3 \%$ cases each. ${ }^{11}$

In the present study, lymph Nodal mass was the most common neck mass (39\%) followed by Nerve sheath tumors (13.2\%) and Miscellaneous (10.2\%). The percentage of other neck masses was less than $10 \%$. The results of this study was consistent with the study by Ravi et al in which commonest neck masses were lymph nodal masses $(32 \%){ }^{3}$

With the sensitivity of MDCT for evaluating the benign lesions was $72.2 \%$, specificity was $69.6 \%$, with a positive predictive value of $78.8 \%$ and for malignant lesions sensitivity $30.4 \%$, specificity was $27.8 \%$, positive predictive value of $21.2 \%$. Gupta et al assessed the role of multislice spiral CT in the evaluation of neck masses. The accuracy of multi-slice CT in predicting the benign or malignant mass and its extent was observed to be very high (97\% and 100\% respectively). The accuracy for predicting the final diagnosis was $62 \%$. In all cases, the extent of the pathology, the local or contiguous spread and vascular involvement predicted by multi-slice CT examination supported well with the surgical findings. ${ }^{12}$

\section{CONCLUSION}

The accuracy of MDCT to predict benign or malignant lesion of the neck massed was observed to be high.

\section{REFERENCES}

1. Alberico RA, Husain SH, Sirotkin I. Imaging in head and neck oncology. Surg Oncol Clin N Am. 2004;13(1):13 -35.

2. Pushpender G, Satish KB, Gopesh M, Vineeta R. Role of Multislice Spiral CT in the Evaluation of Neck Masses. JIMSA 2013; 26(1):51-4.

3. Ravi N, Lakshmeesha M T, Manjappa B H, Naveen K G, Ramesh V, Nagaraj B R. Does MDCT Really Have a Role in the Evaluation of Neck Masses? SSRG International Journal of Medical Science (SSRG-IJMS) 2015; 2 (3).

4. Webb WR. Advances in computed tomography of the thorax. Radiol Clin North Am 1983;21(6):723-39.

5. Protopapas Z, Westcott JL. Transthoracic hilar and mediastinal biopsy. Radiol Clin North Am 2000;38(2):281-91.

6. Lee JKT, Sagel SS, Stanley RJ, Heiken JP, eds. Computed Body Tomography with MRI Correlation, 4th ed. Lippincott Williams and Wilkins 2006:145-214.

7. Kalender WA. Principles and applications of spiral CT. Nucl Med Biol 1994;21(5):693-699.

8. Horton KM, Sheth S, CorlF,Fishman EK.Multidetector row CT: principles and clinical applications. Critical Reviews in Computed Tomography 2002;43(2):143181.

9. Suojanen JN, Mukherji SK, Dupuy DE, et al. Spiral CT in evaluation of head and neck lesions: work in progress. Radiology 1992;183(4):281-283.

10. Thakkar Dhaval K, Khaladkar S, Jantre M, Thakkar Dolly K, Singh A, Kulkarn Vilas M. IOSR Journal of Dental and Medical Sciences, 2015; 14 (8): 66-80.

11. Lasrado S, Prabhu P, Kakria A, Kanchan T, Pant S, Sathian B. Clinico-pathological Profile of Head and Neck Cancers in the Western Development Region, Nepal: A 4-Year Snapshot, Asian Pacific Journal of Cancer Prevention,2012; 12.

12. Gupta P, Bhargava SK., Mehrotra G, Rathi V. Role of Multislice Spiral C.T. in the Evaluation of Neck Masses. JIMSA 2013; 26 (1).

Source of Support: Nil; Conflict of Interest: None

Submitted: 08-08-2019; Accepted: 16-02-2020; Published online: 14-03-2020 